\title{
Conceptos de naturaleza y paisaje (I)
}

Javier Huidobro Pérez-Villamil

\begin{abstract}
"En la ficción de la utopia original de Moro lo ideal existe ya de alguna manera en una isla lejana y ha sido visto por ojos humanos. (...) De manera parecida, la extendida creencia de los cristianos de que el Jardín del Edén, - Paraíso Terrenal, siguió existiendo en algún lugar determinado, aun después de la expulsión de Adán y Eva, alimentó la esperanza de que era posible un estado paradisiaco a este lado del cielo, a la vez que suministraba un modelo del mismo" '.
\end{abstract}

El locus animae entendido como lugar sagrado, desde el diálogo clásico en adelante, tomará especial sentido mediante el pensamiento alegórico medieval. La identidad primitiva entre los dioses y determinados objetos o lugares, considerada como relación simpática entre la alteración del paisaje y de la inconsciencia, posibilitó la analogía de lugares específicos con ideas abstractas. La divinidad fue buscada tanto en ambientes naturales (grutas) o artificiales (templos) como en instantes en los que la intuición no es controlada por la razón, los sueños y las visiones por ejemplo.

Frank E. Manuel y Fritzie P. Manuel, El Pensamiento utópico en el mundo occidental (hasta el siglo Xv1), Madrid, Taurus, 1981, vers. cast. de Bernardo Moreno Carrillo (Harvard Univ. Press, 1979), vol. I.

La intención futura es analizar las crónicas castellanas del siglo xv y las representaciones figurativas de esta época. 
Los elementos que componen las descripciones del paisaje desde las culturas más antiguas hasta finales de la Edad Media presentan constantes que la crítica especializada ha ido señalando en sus textos más relevantes. Sin embargo la mayoría de estos estudios se limitan al repertorio de fragmentos (lo que podríamos llamar «historiografía antológica») sin más objetivo que discernir si lo que se describe es un paisaje como fondo simple de la acción humana o si aparecen los primeros atisbos de un sentimiento estético de la naturaleza.

Sabemos que la antítesis tradicional establecida entre la Edad Media y la cultura grecorromana, por un lado, y su renacimiento en la Italia del siglo $\mathrm{XV}$, por otro, disminuye a medida que se conocen mejor las respectivas épocas. El discurso clásico no durmió durante los siglos oscuros vasarianos sino que fue conservado, enriquecido e interpretado a la luz de lo que el pensamiento medieval daba de $\mathrm{si}^{2}$. También comienzan a ser estudiadas las corrientes orientales que vertieron sobre la cultura occidental un rico aparato iconográfico y una forma nueva de concebir el mundo ${ }^{3}$.

En un primer acercamiento, la representación natural parte de la distinción entre la ciudad y el campo. El paisaje urbano caracteriza la estructura básica del pensamiento, almacén de la sabiduría tradicional y escenario de la vida ordenada. El campo, en un sentido más genérico, corresponde al ámbito de la inconsciencia, referida al bosque y al mar, la naturaleza desordenada y selvática, apartada del hombre ${ }^{4}$.

En este sentido, el locus amoneus, o jardín cerrado, en su versión más clásica de un lugar hermosísimo e intensamente deseable, pero a su vez aislado por barreras físicas o psíquicas, o por su localización remota y aislada, puede verse como una reconciliación entre la ciudad y el campo, entre la consciencia y el inconsciente. La naturaleza, concentrada en la ciudad y su entorno agricola y comercial, se concreta en ocasiones en su aspecto más elaborado: el jardín ${ }^{5}$.

Unas veces es el jardín ordenado y artificial, lugar donde se hace presente la divinidad y espacio adecuado para la meditación; otras veces

2 Ver especialmente Jean SEZNEC, La survivance des Dieux antiques, Paris, Flammarion, 1980 (hay trad. cast. de Juan Aranzadi, Madrid, Taurus, 1983), con abundante bibliografía.

Howard R. PATCH, El otro mundo en la literatura medieval, Madrid, F. C. E., 1956, vers. cast. de Jorge Hernández Campos (Harvard Univ. Press, 1950).

4 Véase el excelente trabajo de Paul PIEHLER, The Visionary Landscape. A study in medieval allegory, London, Edward Arnold, 1971.

5 Guillermo DIAZ-PLAJA, El campo en la literatura española, Madrid 1982. 
es el huerto mundano, sensual, adecuado para el enamoramiento cortés, cárcel de amor al modo del Jardín de la Alegría del Roman de la Rose o del huerto de Melibea en La Celestina.

En las leyendas orientales Patch ha señalado los elementos constantes referidos al Paraíso: el ascenso al cielo, la barrera acuática (referencia a menudo al Árbol de la Vida, o a las aguas de la muerte), el río, el puente y la montaña sagrada. La dificultad de acceder a él determina la selección de los candidatos. En su interior abundan los árboles repletos de frutos preciosos, los ríos que riegan los prados, siempre con referencia a la cualidad especial de cada elemento. Es esta tensión entre lo perteneciente al reino Celestial y lo que corresponde a lo terrenal lo que constituye esta fantasía utópica ${ }^{6}$.

De las leyendas del Oriente Próximo parece provenir el mito del jardín al Este del Edén, especialmente en cuanto a sus antecedentes cristianos: el capítulo II del Génesis y el Cantar de los Cantares. Con frecuencia se menciona al jardín paradisíaco en el que entra Gilgamesh tras conquistar el pueblo del escorpión, donde los árboles, arbustos y viñedos son de piedras preciosas. También el árbol de la cornucopia, limitado por una exultante vegetación y por un muro, de la mitología persa. De estas y otras fuentes habrían derivado algunos aspectos del Paraíso Terrenal cristiano, como la riqueza de piedras preciosas y materiales brillantes tan a menudo representados en las ilustraciones miniadas, y la caracterización de la Montaña del Mundo, lugar donde tradicionalmente se sitúa el jardín del paraíso. Una de las delicias del jardín será, por influencia latina, la contemplación del mar y la llanura ${ }^{7}$.

En la novela griega las descripciones paisajisticas con intención no geográfica se atribuyen a la "ecfrasis" de la Segunda Sofística ${ }^{8}$. En ella se destacan los valores positivos de la naturaleza; la vista del mar es presentada como «un placer más que añadir a las delicias del jardín de Lamón", siempre observado desde la seguridad de la costa. Cuando interviene el hombre se convierte en lugar ameno visto como escenario para la acción humana, únicamente válido para ser contemplado por los diferentes sentidos. La belleza se expresa en términos de altura (de los árboles, etc.) y abundancia de las especies (flores, pájaros, frutos...). Este ambiente idílico encuentra su oposición en los elementos perturba-

5 Howard R. PATCH, obra citada.

7 Para las referencias concretas ver MANuEL, obra citada.

8 Francisco Romero Cruz, Naturaleza y paisaje en la literatura griega tardia, Salamanca, Gráf. Europa, 1973. 
dores de la naturaleza: el bosque, donde se suceden la flora silvestre, las fieras, los raptos (lo desordenado, salvaje), y la ciudad (de donde proceden la mayoria de los elementos negativos).

En ocasiones, el paisaje no es sólo un plano de fondo, una dimensión espacial para la acción. También proporcionará un elemento expresivo del estado psicológico de los personajes. Esta animación del paisaje se remonta a la época Arcaica griega en que la naturaleza era mostrada en concordancia o disonancia con los sentimientos del personaje. En el lugar ameno es imprescindible la presencia de seres humanos o divinos que sancionen la belleza del lugar.

Consecuencia de todo esto es la evolución experimentada por el paisaje en estos primeros tiempos: en su carácter ideal destaca ante todo su utilidad para el hombre (abundancia, fertilidad, clima agradable, árboles frutales, animales de trabajo, campesinos...) unido al valor intrínseco de su goce estético centrado en el descanso que ofrece (plantas bellas y cómodas, animales cantores, fuentes frescas...).

Con el tiempo, la concepción primitiva como residencia ideal de la divinidad se va perdiendo y será la presencia del hombre la que valore su utilidad y belleza. Los planos estético y erótico llegan a fundirse en el amado o la amada. De ellos proviene la fertilidad del paisaje otoñal y el aumento de sensaciones táctiles.

Grecia desarrolló la creencia en una época de abundancia y de inocencia, una edad de oro sobre la tierra, un estado humano perfecto surgido en el remoto pasado, el mito de los Campos Elíseos. En Homero el Elíseo es un lugar reservado a los héroes, donde no llega la muerte ${ }^{9}$.

Filón de Alejandría, en el siglo । d. C., sometió al jardín del Edén a una nueva interpretación. Fue el primero en designar como "alegórico» su sistema de lectura de las Escrituras. Dentro de la tradición platónica, consideró los frutos del jardín como virtudes del alma. Filón prefiere ver en el paraíso una alegoría de la sabiduría, un conocimiento de lo divino y de lo humano, una reproducción del jardín celeste con los cuatro ríos simbolizando las cuatro virtudes. El Edén podia interpretarse a partir de ahora como una tipología del paraiso futuro del cielo ${ }^{10}$.

De Ovidio deriva sobre todo el entendimiento del paisaje como manifestación y contraste de potencias y estados espirituales, que pasarán

9 Homero, La Odisea, trad. de Lusi Segalá y Estabella, Madrid, Espasa Calpe, 1971.

10 FiLON DE ALEJANDRIA, “Preguntas y respuestas sobre el Génesis», Obras Completas, trad. de José María Triviño, Buenos Aires, Acervo Cultural, 1975. 
a la literatura medieval. En ella se acentúa el interés por situar al hombre en armonía con el orden moral y espiritual del universo. Virgilio fue también figura decisiva en la transmisión del mito de la edad de oro. El mundo medieval verá en su obra un anuncio del cristianismo.

El pensamiento medieval busca en la forma de las cosas su significación, partiendo de ella imagina el contenido que se ignora. Hugo de San Víctor en su Didascalicon dividia el comentario de un texto en tres grados: literal, de significado y de sentido profundo. A la última comprensión no se llegaba sin la exégesis o comentario. La técnica medieval desarrollada para identificar estos diversos grados interpretativos fue heredada de los siglos anteriores: la alegoría. La lectura alegórica proviene de la nueva interpretación que los mitos religiosos y poéticos griegos hallaron alrededor del siglo vII a. C. La exégesis alegórica multiplicaba los sentidos en un texto desplegando sus ecos y conexiones. De esta manera, Jerusalén (literalmente Ciudad de los Judíos) si incluía la presencia sagrada a través de palabras o elementos místicos, alegorizaba la iglesia de Cristo; pero si anagógicamente se destaca la referencia a la vida futura, significaba la Ciudad de Dios, la celeste.

Otras técnicas de comprensión de las Escrituras permitian al hombre medieval interpretar sus significados y actualizarlos, como la tropología y la tipología, pero sólo el símbolo permitía transmitir conceptos incomunicables por medio de la palabra o de la escritura. Con el símbolo se transmite un orden de las cosas, un misterio. La tipología acercaba realidades cronológicamente lejanas, como el Antiguo y el Nuevo Testamento ${ }^{11}$.

San Agustín vio en las referencias biblicas al jardín del Edén no sólo el paraíso fisico de la Creación sino también un paraíso espiritual donde el alma estaría en un estado de gracia. A menudo, los teólogos medievales enfrentaron en sus comentarios los jardines de la piedad y del deseo. Estas visiones alegóricas, originadas en el cristianismo primitivo continuaron a lo largo de la Edad Media. Las doce montañas del Pastor de las Hermas (segunda centuria después de Cristo) se relaciona con doce estados espirituales, y el jardín de Methodius (tercera centuria), donde se celebra el banquete del Symposium representa un lugar ameno y cerrado que alegoriza el tópico de la virginidad.

11 Ver Alberto VarVaro, Literatura románica de la Edad Media. Estructuras y formas, Barcelona, Ariel, 1983 (primera edición 1968). 
Que la naturaleza no es sólo un fondo o decorado sino que interviene en la acción humana queda perfectamente destacado en el Architrenius de Johannis de Altavilla (siglo XII), donde un joven acusa a ésta de no protegerle del vicio. En la naturaleza se contienen las "potentiae», dioses paganos, criaturas monstruosas. Así aparecen metáforas concebidas en términos de paisaje: el Monte de la Ambición, el Infierno de la Presunción, etc. Este primero es visto como una parodia del jardín edénico: en lo alto de esta montaña la infertilidad no existe, pero es un lugar de frustración y engaño. Sólo la «moderantia» puede evitar la ambición mundana que supone la búsqueda del paraíso.

De este motivo aparece como su ejemplo más representativo el $R o-$ man de la Rose. En la representación del jardín como "hortus conclusus» de simbolismo mariano Orozco destaca la ficción alegórica de Juan Ochoa, en la que Cristo es presentado como el "sagrado hortelano" y la Iglesia como el vergel por Él creado ${ }^{12}$. Del jardín como escenario cómplice del discurso amoroso está lleno el Romancero popular. Debemos recordar que la Edad Media alegorizó como representación del pecado original el paisaje salvaje sin cultivar.

Es conocido, asimismo, el valor que los teólogos medievales concedían a lo sensible como medio de elevación hacia la contemplación de lo más alto e invisible. Hay que defender en todo caso la posibilidad de valorar lo sensible en sí mismo, por la belleza que encierra, distinta de su posible significación alegórica, lo que en la Edad Media, como ya demostró De Bruyne, se había hecho netamente.

A finales del siglo XII el abad Joaquín se refugia en las montañas de San Giovanni in Fiore. lluminado por una visión, se le revelaron algunos pasajes crípticos del Antiguo Testamento. Escribirá los estatutos de una nueva orden que preparará el reino del Espíritu Santo en la Tierra que suplantaria a la Iglesia de Cristo ${ }^{13}$.

El jardín medieval fue también objeto de las visiones parodiadas acerca del amor terrenal. Este «jardín secreto", como lo llama Piehler, puede tener su origen en la ambigüedad manifestada en sus antecedentes bíblicos: la atracción de la primera caída en sí misma, y la asociación del "hortus conclusus" con el cuerpo de la mujer amada. Este jardín cerrado llegará a adquirir el valor de símbolo de la moralidad privada

12 Emilio Orozco Diaz, Paisaje y sentimiento de la naturaleza en la poesía española, Madrid 1974. citada.

${ }^{13}$ Concordancia entre el Antiguo y el Nuevo Testamento. Citado por MANUEL, obra 
opuesta a la Iglesia, de difícil acceso por su cerramiento o por su secreta existencia. En el jardín se dieron forma un gran número de asociaciones que describieran los aspectos eróticos de la vida cortesana ${ }^{14}$. En el Trattato d'Amore de Andrea Capellano (siglo XII) el "amoris aula" es presentado como un lugar cerrado con tres puertas, dónde sólo una corresponde a las mujeres con "mesura». La "amoris curia» es regada con fuentes que sacian la sed de todas las mujeres que han amado correctamente; su conocimiento es necesario para poder obrar de forma adecuada. En el contemporáneo Altercatio Phyllidis et Florae, Cupido reside en un lugar ameno con corrientes murmurantes, brisas suaves que traen aromas de mirra, música de instrumentos y de aves, y placeres exóticos. La llegada al lugar ameno supone siempre la solución a los problemas planteados. La búsqueda de la armonía con el entorno lleva al hombre medieval a este autorreconocimiento con la naturaleza.

La fantasía utópica acerca del Paraíso operó en el inconsciente de amplios sectores de la población. La Iglesia quiso mantener vivo el anhelo de un estado de la humanidad pasado que tendría que volver ${ }^{15}$.

14 Paul PIEHLER, obra citada.

Ver tambien D. W. Robertson, "The Doctrine of Charity in Medieval Literary Gardens: a topical aproach through Symbolism and Allegory", Speculum, enero 1951, pág. 24 a 49.

15 A partir del siglo xill la relación del hombre con la naturaleza y la espiritualización del amor subsiguiente altera notablemente estos conceptos. El campo comienza a ser valorado desde la ciudad, y el paisaje se categoriza de modo diferente. Es entonces cuando las imago mundi construyen lo fundamental del paisaje. Pero sobre ello, del franciscanismo hasta las Crónicas del siglo xv, volveremos en la próxima ocasión. 


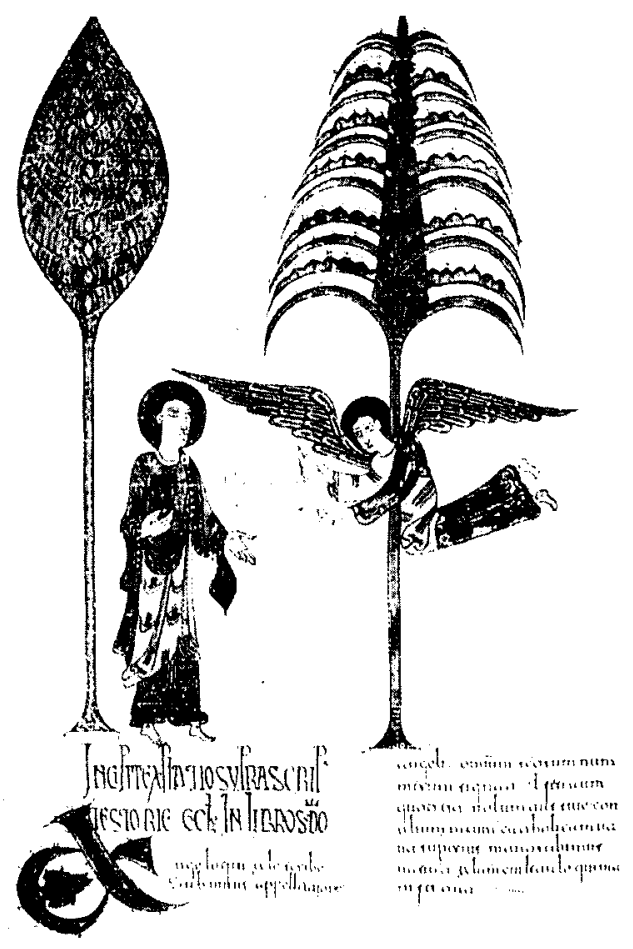

Fig. 1. La creación del hombre. Biblia del Panteon. Siglo XII. 


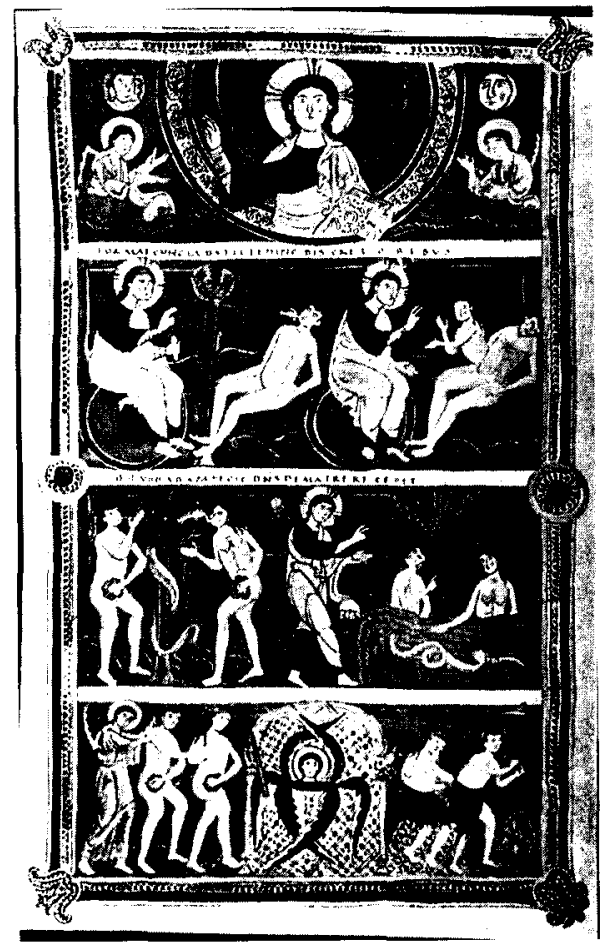

Fig. 2. Beato de Fernando I y D." Sancha. 